\title{
ESTIMATIVA DA ACIDEZ POTENCIAL PELO MÉTODO SMP EM SOLOS OCORRENTES NO NORDESTE PARAE NSE ${ }^{(1)}$
}

\author{
M. A. P. GAMA(2), L. I. PROCHNOW(3) \& J . R. N. F. GAMA(4)
}

\begin{abstract}
RESUMO
A determinação da aci dez potencial (H + Al) em amostras de solo pelo método do acetato de cálcio 0,5 mol L-1 a pH 7,0 (método usual) é normal mente utilizada pelos laboratóri os no Brasil. Outros métodos que apresentam vantagens quanto à rapidez e operacionalidade têm sido testados em várias regiões com sucesso, 0 que ainda não ocorreu para os solos da região nordeste do estado do Pará. Por essa razão, vinte e sete amostras de solo da região nordeste do Pará foram analisadas quanto à acidez potencial pelo método usual. $\mathbf{O}$ pH de equilíbrio no extrato acetato-solo antes da titulação foi determinado, e os valores obtidos relacionados com os teores de H + Al. Determinou-se, ainda, o pH da solução de equilíbrio da agitação das amostras de solo com solução-tampão SMP, sendo os valores relacionados com acidez potencial obtidos pelo método usual. Dos modelos testados, o quadrático foi o que melhor se ajustou às duas situações. Verificou-se elevada relação entre os teores de H + Al, obtidos pelo método usual, e os valores de pH do extrato acetato-solo e pH SMP. A maior amplitude de valores encontrada para o pH SMP, em relação aos obtidos pelo pH do extrato acetato-solo, evidencia maior precisão para o primeiro.
\end{abstract}

Termos de indexação: reação do solo, acidez de reserva, análise química do solo.

(1) Parte da Tese de Mestrado, apresentada à E scola Superior de Agricultura “Luiz de Queiroz" - ESALQ. Executado com auxílio da CAPES. Recebido para publicação em janeiro de 1999 e aprovado em maio de 2002.

(2) Pós-Graduando do Curso de Solos e Nutrição de Plantas, Escola Superior de Agricultura "Luiz de Queiroz" - ESALQ/USP. Caixa Postal 9, CEP 13418-900 Piracicaba (SP). Bolsista PICDT/CAPES.

(3) Professor Doutor do Departamento de Solos e Nutrição de Plantas, ESALQ/USP. E-mail: liprochn@esalq.usp.br

(4) Pesquisador Doutor da Embrapa Centro de Pesquisa Agroflorestal da Amazônia Oriental. Belém (PA). 


\title{
SUMMARY: ESTIMATION OF POTENTIAL SOIL ACIDITY BY THE SMP METHOD IN THE NORTHEAST OF PARÁ STATE, BRAZIL
}

\begin{abstract}
The determination of the potential acidity $(\mathrm{H}+\mathrm{Al})$ of soil samples by the calcium acetate $0.5 \mathrm{~mol} \mathrm{~L}^{-1} \mathrm{pH} 7.0$ method (conventional method) is most used in Brazilian laboratories. Other methods, which aremorepractical for routineanalyses, havebeen tested with success for various soil groups, but not for thoselocated in thenortheast of theState of Pará. With this objective, twenty-seven representative soil samples were analyzed by the conventional $\mathrm{Ca}(\mathrm{OAc})_{2}$ method. ThepH of equilibrium in thecal cium acetatesoil suspension was determined before titration and the obtained values related to the $\mathrm{H}+\mathrm{Al}$ contents by the $\mathrm{Ca}(\mathrm{OAC})_{2}$ method. The $\mathrm{pH}$ in the equilibrium suspension of agitated soil samples was al so determined with theSMP buffer solution and thevalues related to thepotential acidity obtained by the $\mathrm{Ca}(\mathrm{OAc})_{2}$ method. The quadratic model was best fit for both situations. Results showed an elevated relation between theamount of $\mathrm{H}+\mathrm{Al}$ estimated by thecalcium acetate method and the $\mathrm{pH}$ of the acetatesoil suspension or the $\mathrm{pH}$ SMP. The higher amplitude of the data found for the pH SMP qualifies this method as more precise for the quantification of potential acidity in those soils.
\end{abstract}

Index terms: soil reaction, potential acidity, chemical soil analysis.

\section{INTRODUÇÃO}

A determinação da acidez potencial $(\mathrm{H}+\mathrm{Al})$ serve para avaliar a fertilidade dos solos e tem sido realizada pela maioria dos laboratórios de análise química de solo no Brasil. Através dela, é possível aferir-se o poder-tampão do solo, calcular indiretamente a capacidade de troca catiônica ( $\mathrm{T}=$ $\mathrm{SB}+(\mathrm{H}+\mathrm{Al}))$ e, ainda, recomendar doses adequadas de corretivo.

O método de determinação que utiliza a solução deacetato de cál cio 0,5 mol L-1 ajustada para pH 7,0, seguido de titulação do extrato com $\mathrm{NaOH}$ $0,025 \mathrm{~mol} \mathrm{~L}^{-1}$, é usado por grande parte dos laboratórios no Brasil. Freitas et al. (1968), trabal hando com sol os deSão Paulo, observaram que as quantidades de corretivo calculadas a partir do valor de $\mathrm{H}+\mathrm{Al}$, obtido através do acetato, foram similares às obtidas com curva de neutralização dos solos. Pavan et al. (1996) ressaltaram a importância dessemétodo, uma vez que ind ui nãoapenas a acidez ativa e trocável, mas também a de reserva ou dependente de $\mathrm{pH}$.

Essemétodo, no entanto, étrabal hoso eapresenta desvantagens, destacando-se: maior tempo para execução, presença no mercado de acetato de cálcio de baixa qualidade, preparo diário de soluções de acetato e problemas de nitidez no ponto de viragem quando os solos são ricos em matéria orgânica (Quaggio et al., 1985; Raij et al., 1987; Pavan et al., 1996).

Considerando os problemas apontados, outros métodos de determinação da acidez potencial têm sido propostos, destacando-se a avaliação potenciométrica, pela utilização da leitura do $\mathrm{pH}$ da suspensão resultante da agitação de amostra de solo com sol ução-tampãoSMP. Essemétodo, inicialmente sugerido por Shoemaker et al. (1961) para avaliar a necessi dade de calagem, foi avaliado posteriormente por outros pesquisadores (McLean et al., 1966; Freitas et al ., 1968; Webber et al., 1977; Quaggio et al., 1985).

Raij et al. (1979), trabal hando com amostras de sol os ocorrentes no estado de São Paulo, verificaram alta relação entre o pH de equilíbrio de suspensões de solo:água:solução-tampão SMP e os teores de $\mathrm{H}+\mathrm{Al}$ determinados pelo método do acetato de cálcio. Desta forma, os autores sugeriram a determinação da acidez potencial por meio da medida do $\mathrm{pH}$ de equilíbrio da suspensão de solução SMP com o solo, após agitação. A utilização desse método exige o estabel ecimento de equações de regressão para cada região, o quefoi feito, entreoutros, por Quaggio et al. (1985) e Pereira et al . (1998).

Pereira et al. (1998), além de avaliarem o uso da solução-tampão SMP, também verificaram ser possível uma adaptação do método do acetato de cál cio para determinação da acidez potencial. Para tanto, observaram haver uma estreita correlação entre os valores de acidez potencial e os de $\mathrm{pH}$ da solução de acetato de cálcio após o contato com o sol o. A vantagem desse método consiste na utilização da leitura de $\mathrm{pH}$ que evitaria o processo detitulação com hidróxido de sódio.

No Pará, os laboratórios de análise química de sol o têm utilizado o método do acetato de cál cio para a determinação da acidez potencial. O objetivo deste trabal ho foi estudar a utilização dos métodos do pH SMP e pH da suspensão solo-acetato de cál cio, como forma de estimar a acidez potencial em solos da região nordeste do Pará. 


\section{MATERIAL E MÉTODOS}

Foram utilizadas vinte e sete amostras de solos representativos do nordeste paraense, col etadas da camada superficial (0-20 cm de profundidade), nos meses de janeiro a março de 1998. As análises laboratoriais e estatísticas foram realizadas entre os meses de abril eagosto de 1998. Nessas amostras, os teores de matéria orgânica variaram de 12 a $71 \mathrm{~g} \mathrm{dm}^{-3}$, o $\mathrm{pH}$ em $\mathrm{CaCl}_{2}$ variou de 3,6 a 6,6 e os valores de CTC ficaram entre 46 e $208 \mathrm{mmol}_{\mathrm{c}} \mathrm{dm}^{-3}$.

A acidez potencial foi extraída com acetato de cálcio 0,5 mol L-1 a pH 7,0 e determinada por titulação com NaOH 0,025 mol L-1. Para tanto, em erlenmeyer de $250 \mathrm{~mL}$, adicionaram-se $5 \mathrm{~cm}^{3}$ de terra fina seca ao ar (TFSA) e $50 \mathrm{~mL}$ de solução extratora. A pós agitação da suspensão terra-acetato por 15 min e repouso por uma noite, tomou-se uma alíquota de $25 \mathrm{~mL}$ do líquido sobrenadante, na qual foram adicionadas três gotas de solução al coól ica de fenolftaleína a 3 dag $L^{-1}$ e determinou-se a quantidade de $\mathrm{H}+\mathrm{Al}$ por meio de titulação com solução de $\mathrm{NaOH} 0,025 \mathrm{~mol} \mathrm{~L}^{-1}$. Os cál culos do teor final de $\mathrm{H}+\mathrm{Al}$, em $\mathrm{mmol}_{\mathrm{c}} \mathrm{dm}^{-3}$, foram realizados, subtraindo-se do volume gasto na titulação da amostra o volume gasto na titulação da prova em branco. Antes da titulação, determinou-se o valor do $\mathrm{pH}$ das alíquotas de $25 \mathrm{~mL}$, valor esse que foi utilizado para posterior correlação com os dados finais de $\mathrm{H}+\mathrm{Al}$ obtidos pelo método usual.

Nas mesmas amostras, determinou-se o pH SMP por meio do método proposto por Raij et al. (1987). Estudos de correlação e regressão foram realizados entre os val ores deH +Al determinados pel o método doacetato eos valores de pH SMP epH da suspensão de acetato de cálcio-solo.

\section{RESULTADOS E DISCUSSÃO}

Os val ores deacidez potencial $(\mathrm{H}+\mathrm{Al})$, extraídos por acetato de cálcio, variaram de 8 a $126 \mathrm{mmo}_{\mathrm{C}} \mathrm{dm}^{-3}$ e os de pH SMP de 5,1 a 7,6. Verificou-se, entre as duas variáveis, uma alta correlação $(r=-0,91)$, inversamente proporcional, ou seja, com aumento do pH SMP, observou-se um decréscimo nos valores de $\mathrm{H}+\mathrm{Al}$. O modelo quadrático ajustou-se aos resultados obtidos por meio da equação $\hat{Y}=786,3$ $201,73 X+13,294 X^{2}\left(R^{2}=0,90\right)$, na qual Y representa os valores de $\mathrm{H}+\mathrm{Al}$ e $\mathrm{X}$ os de pH SMP (Figura 1 ). Com essa equação, e dentro da amplitude de val ores de pH SMP observados, foram estimados os valores de acidez potencial (Quadro 1).

Esses resultados são similares aos obtidos por Raij et al . (1979), Quaggio et al . (1985), Pereira et al . (1998), entre outros, que também verificaram a possibilidade de estimar a acidez potencial pelo método SMP. As diferentes equações obtidas entre o presente trabalho e os demais citados anteriormente confirmam a importância do ajuste desse método para cada grupo desol os de diferentes regiões.

A alta correl ação entre os valores de $\mathrm{H}+\mathrm{Al}$ e o $\mathrm{pH}$ da suspensão de solo - acetato de cálcio 0,5 mol L-1 ( $r=-0,93)$, mostrou-se inversamente proporcional. O model o quadrático ajustou-se aos resultados, com um $\mathrm{R}^{2}$ de 0,92 (Figura 2). Esses resultados foram similares aos obtidos por Pereira et al. (1998) até mesmo na pequena variação encontrada para os valores de pH da suspensão de acetato de cál cio.

Com a pequena amplitude observada para os valores de $\mathrm{pH}$ da suspensão de acetato-solo $(6,1 \mathrm{a}$ 6,8 ) (Figura 2), acredita-se não ser adequado e seguro

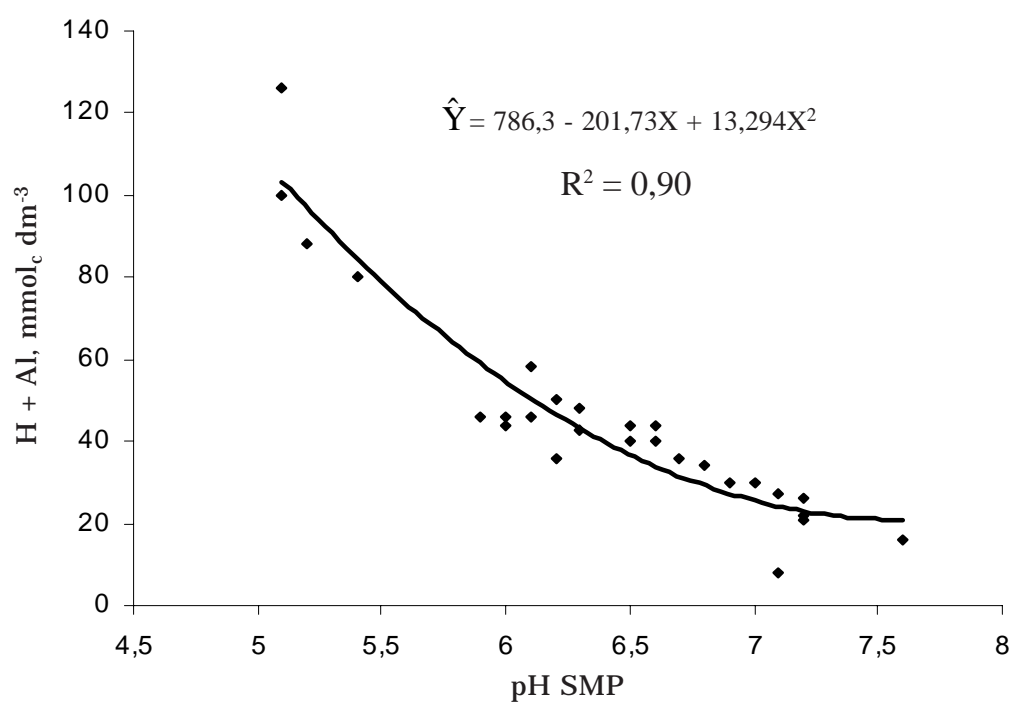

Figura 1. Relação entre acidez potencial (H + Al) extraída com acetato de cálcio e pH SMP em 27 amostras de terra do nordeste paraense. 
Quadro 1. Estimativas de acidez potencial a partir do pH SMP para solos do nordeste paraense ${ }^{(1)}$

\begin{tabular}{|c|c|c|c|c|c|}
\hline pH SMP & $\mathbf{H}+\mathbf{A l}$ & pH SMP & $\mathbf{H}+\mathbf{A l}$ & pH SMP & $\mathbf{H}+\mathbf{A l}$ \\
\hline & $\mathrm{mmol}_{\mathrm{c}} \cdot \mathrm{dm}^{-3}$ & & $\mathrm{mmol}_{\mathrm{c}} \cdot \mathrm{dm}^{-3}$ & & $\mathrm{mmol}_{\mathrm{c}} \cdot \mathrm{dm}^{-3}$ \\
\hline 5,1 & 103,3 & 6,1 & 50,4 & 7,1 & 24,2 \\
\hline 5,2 & 96,8 & 6,2 & 46,6 & 7,2 & 23,0 \\
\hline 5,3 & 90,6 & 6,3 & 43,0 & 7,3 & 22,1 \\
\hline 5,4 & 84,6 & 6,4 & 39,8 & 7,4 & 21,5 \\
\hline 5,5 & 78,9 & 6,5 & 36,7 & & \\
\hline 5,6 & 73,5 & 6,6 & 34,0 & & \\
\hline 5,7 & 68,4 & 6,7 & 31,5 & & \\
\hline 5,8 & 63,5 & 6,8 & 29,3 & & \\
\hline 5,9 & 58,9 & 6,9 & 27,3 & & \\
\hline 6 & 54,5 & 7,0 & 25,6 & & \\
\hline
\end{tabular}

(1) $\hat{\mathrm{Y}}=786,3-201,73 \mathrm{X}+13,294 \mathrm{X}^{2}$, onde $\mathrm{Y}=\mathrm{H}+\mathrm{Al}$, em $\mathrm{mmol}_{\mathrm{c}} \mathrm{dm}^{-3}$, e X $=\mathrm{pH}$ SMP.

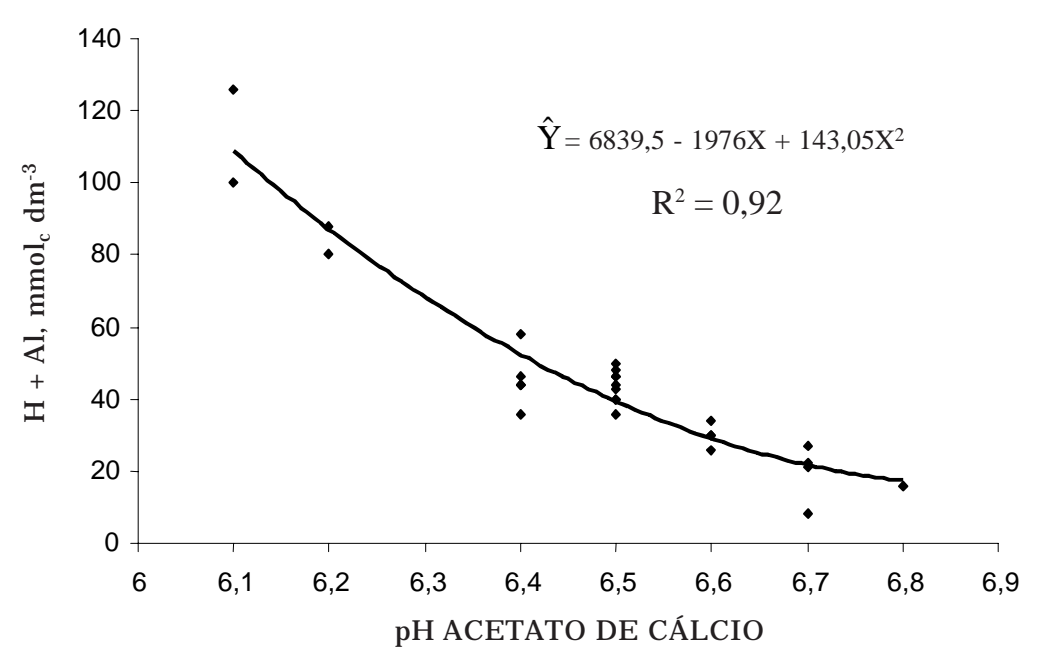

Figura 2. Relação entrea acidez potencial (H + Al) e o pH da suspensão de acetato de cálcio em 27 amostras de terra do nordeste paraense.

o uso desse método para determinar indiretamente a acidez potencial, visto que a variação de apenas 0,1 unidade de $\mathrm{pH}$ provoca variação de até $21,7 \mathrm{mmol}_{\mathrm{c}} \mathrm{dm}^{-3}$ de $\mathrm{H}+\mathrm{Al}$. Esse fato, diante da imprecisão da determinação do $\mathrm{pH}$, constitui problema sério para adoção dessa alternativa para estimar a acidez potencial dos solos do nordeste paraense.

\section{CONCLUSÃO}

O método SMP para estimar a acidez potencial de solos do nordeste paraense mostrou-se viável através de ajuste de equação de segundo grau, relacionando os teores de $\mathrm{H}+\mathrm{Al}$, determinados pelo método do acetato de cál cio $0,5 \mathrm{~mol} \mathrm{~L}^{-1}$, eas leituras de $\mathrm{pH}$ SMP.

\section{LITE RATURA CITADA}

FREITAS, L.M.M.; PRATT, P.F. \& VETTORI, L. Testes rápidos para estimar as necessidades em calcário de alguns solos de São Paulo. Pesq. Agropec. Bras., 3:159-164, 1968.

MCLEAN, E.O.; DUMFORD, S.W. \& CORONEL, F. A comparison of several methods of determining lime requirements of soils. Soil Sci. Soc. Am. Proc., 30:26-30, 1966.

PAVAN, M.A.; OLIVEIRA, E.L. \& MIYAZAWA, M. Determinação indireta da acidez extraível do solo $(\mathrm{H}+\mathrm{Al})$ por potenciometria com a solução-tampão SMP. Arq. Biol. Tecnol., 39:307-312, 1996.

PEREIRA, M.G.; VALLADARES, G.S.; SOUZA, J .MP.F.; PÉREZ, D.V. \& ANJ OS, L.H.C. Estimativa da acidez potencial pelo método do pH SMP em solos do Estado do Rio de J aneiro. R. Bras. Ci. Solo, 22:159-162, 1998.

QUAGGIO, J.A.; RAIJ , B. van. \& MALAVOLTA, E. Alternative use of the SMP-buffer solution to determine lime requirement of soils. Comm. Soil Sc. Plant Anal., 16:245260, 1985. 
RAIJ, B. van; CANTARELLA, H. \& ZULLO, M.A.T. O método tampãoSMP para determinação da necessidade de calagem de sol os do Estado deSão Paulo. Bragantia, 38:57-69, 1979.

RAIJ , B. van.; QUAGGIO,J .A.; CANTARELLA, H.; FERREIRA, M.E; LOPES, A.S. \& BATAGLIA, O.C. Análise química do solo para fins de fertilidade. Campinas: Fundação Cargill, 1987. 170p.
SHOEMAKER, H.E.; MCLEAN, E.O. \& PRATT, P.F. Buffer methods for determining lime requirements of soils with appreciable amounts of extractable aluminum. Soil Sci. Soc. Am. Proc., 25:274-277, 1961.

WEBBER, M.D.; HOYT, P.B.; NYBORG, M. \& CORNEAU, D. A comparison of lime requirement methods for acid canadian soils. Can. J. Soil Sci., 57:361-370, 1977. 
M.A.P. GAMA et al.

R. Bras. Ci. Solo, 26:1093-1097, 2002 